\title{
Pleuro-pulmonary disease in central South Africa: A thoracic surgical deficiency
}

\author{
A Linegar, G van Zyl, F Smit, P Goldstraw
}

To the Editor: We wished to estimate the performance gap between thoracic surgical service provision and the burden of thoracic surgical disease in central South Africa (SA). We compared burden of disease data to the number of thoracic operations performed for inflammatory pleuro-pulmonary disease and primary lung cancer. The performance gap was estimated to be a factor of 1:20 for lung cancer and 1:10 for thoracic surgery as a whole. The extent of under-provision of thoracic surgical services in central SA demonstrates that urgent major health care system reforms are required at all levels to address the significant performance gap between service provision by thoracic surgery and the burden of disease in central SA.

\section{Background}

Public health service delivery in SA is in crisis, making health reform at every level a complex issue of national importance. ${ }^{1}$ This is particularly true for thoracic surgery in central SA, where its provision for the population of approximately 4.2 million people dependant on state health care has been rudimentary. Inflammatory pleuro-pulmonary diseases are mostly curable, and lung resection offers the best chance of cure in appropriately selected patients with lung cancer. However, if poorly managed, these patients suffer needless morbidity, unemployment and premature mortality, with serious implications for their dependants and society.

The study was undertaken in response to the evident performance gap between the high burden of thoracic disease and the level of thoracic surgery service provision in the region. Inflammatory pleuro-pulmonary disease in the study includes pulmonary tuberculosis (PTB), bronchiectasis, destructive pneumonia and pyogenic empyema.

Poverty, lack of opportunities and inadequate health care are major problems facing the central SA community, where $57 \%$ of people live below the poverty line, and $43 \%$ of those between 15 and 64 years old are unemployed. ${ }^{2,3}$

We aimed to estimate the performance gap between thoracic surgical service provision and the burden of thoracic surgical disease in central SA.

Department of Cardiothoracic Surgery, Faculty of Health Sciences, University of the Free State and Universitas Hospital, Bloemfontein

A Linegar, MB ChB, FC (Cardio) SA, PhD

G van Zyl, MB ChB, MFamMed, MBA, PhD

F Smit, MB ChB, MMed (Cardiothor)

P Goldstraw, FRCS (Eng)

\section{Method}

Data were collected for the period 2004 - 2006. Burden of disease data were obtained from publications originating from: (i) the Burden of Disease Unit of the Medical Research Council of SA; (ii) the SA National Department of Health (DoH), Statistics SA and the Health Systems Trust; and (iii) the National Cancer Registry (NCR) of 1999.

Thoracic surgical activity was quantified from the operation records of: (i) the Departments of Cardiothoracic Surgery and General Surgery at Universitas Hospital (University of the Free State); and (ii) the Departments of General Surgery at the 7 regional hospitals in central SA.

Actual service provision by surgeons was calculated in terms of whole time equivalents (WTEs), defined as the percentage of working time spent by each cardiothoracic surgeon on thoracic surgery. Approval for the study was obtained from the Ethics Committee of the University of the Free State (ETOVS 206/06).

\section{Results}

\section{The study population}

The population of central SA is approximately 4.6 million people, of whom 4.2 million depend on state health care provision. The age group pyramid is typical of a young developing country, with $86 \%<49$ years old. ${ }^{4}$ HIV infection accounts for $32.3 \%$ of annual mortalities in Free State Province (FS). Thoracic pathology, including tuberculous and nontuberculous inflammatory pleuro-pulmonary diseases, HIV, tobacco-related lung disease, thoracic trauma and thoracic malignancies, represent 7 of the 20 top mortality categories. ${ }^{5}$

\section{Burden of disease in non-tuberculous pleuro- pulmonary disease}

Non-tuberculous lower respiratory tract infections are a leading cause of death in SA, accounting for $6 \%$ of all deaths in the FS annually. ${ }^{6}$ Inflammatory lung disease is the most published topic in the SA thoracic surgical literature. ${ }^{7}$ While it was not possible to numerically quantify its caseload to the thoracic surgery burden of disease, such diseases represented the largest proportion ( $28 \%$ ) of the thoracic surgical workload in central SA.

\section{Burden of disease in PTB}

The reported incidence of sputum-positive PTB in the FS during 2006 was 322 per 100000 of the population, and is steadily increasing; 125496 new cases of sputum-positive PTB are reported in SA annually, of which approximately 15272 are in central SA. ${ }^{8,9}$

PTB presents to the thoracic surgeon in its active and sequela forms. Sequela manifestations include bronchiectasis, destroyed lung, aspergilloma and chronic pyogenic empyema 
in the presence of broncho-pleural fistula with thick visceral pleural peel and entrapped lung. Patients with complicated expressions of the disease usually present late in the course of their disease, are frequently generally debilitated, and are often HIV positive.

PTB surgery represented $9 \%$ of the operation load at Universitas Hospital during the study. Despite the high incidence and severity of this disease, a systematic review of the SA thoracic surgical literature between 1955 and 2006, revealed only 12 publications..$^{10}$ The available data did not make it possible to quantify the expected surgical caseload for PTB.

\section{Estimated number of resections in primary lung carcinoma}

The National Cancer Registry (NCR) ${ }^{11}$ reported an overall agestandardised incidence rate (ASIR) of 15.2 per 100000 in 1999, which increases in men to 28 per 100000 in the 50 - 54 age group and peaks in the 65 - 69 age group at 89 cases per 100000.

The resectability rate in lung cancer is $10-20 \%{ }^{12,13}$ Based on a resectability rate of $10 \%$, and the estimated annual mortality rate for lung cancer, ${ }^{5,6,14}$ the annual potential number of lung resections was calculated for central SA (Table I).

NCR data ${ }^{11}$ indicated that approximately 70 lung resections should be performed annually in central SA (Table I). This figure concurred with calculations based on the ASIR. An average of 4 lung resections for lung cancer were performed annually during the study (Table II).

\section{Thoracic surgeon provision in central SA}

There were 4 registered cardiothoracic surgeons in state practice in central SA during the study; 3 surgeons each spent $10 \%$ of their time on thoracic surgery. The WTE allocation to thoracic surgery by cardiothoracic surgeons was therefore 0.3 surgeons per 4.2 million people, which equates to 0.07 surgeons per million of population.

\section{Thoracic surgical activity in central SA}

Universitas Hospital was the only hospital in central SA where lung resections were performed. No lung resections were performed by non-thoracic surgeons. Open drainage of empyemata was rarely performed by general surgeons at regional hospitals.

Universitas Hospital theatre records showed an average of 166 thoracic operations per year during the study. Of these, inflammatory pleuro-pulmonary disease including TB represented the largest single portion (40\%); pyogenic empyema and PTB were $9 \%$ each; and therapeutic resections for lung cancer $(N=11)$ represented only $2 \%$ of all operations (Table II).

\section{The performance gap}

The performance gap in lung cancer was quantified to be a factor of approximately 20. It was not possible to numerically quantify the performance gap in inflammatory pleuropulmonary disease.

\section{Discussion}

The average of 166 operations per annum represents 40 operations per million of population, which compares poorly with 91 operations per million in the teaching departments of cardiothoracic surgery in $\mathrm{SA}^{10}$ and 400 operations per million in the $\mathrm{UK}^{15}$ and Germany. ${ }^{16}$ Similarly, the number of thoracic surgeons for the population of central SA is extremely low (0.07 thoracic surgeons per million), whereas this figure varies from 2 surgeons per million in the Western Cape province to 1 surgeon per million for Gauteng and KwaZulu-Natal. ${ }^{10}$

The estimated annual burden of 70 lung cancer resections underestimates the surgical workload. Furthermore, the diagnostic, staging and palliative interventional workload is much larger than that for the lung resections, of which there is little in central SA.

The lack of important clinical data made it impossible to quantify the thoracic surgical performance gap between burden of disease and service delivery for tuberculous and

Table I. Estimated number of lung resections for lung cancer required annually, ${ }^{5,11,14}$

\begin{tabular}{lll}
\hline & SA & Central SA \\
\hline Population & 47000000 & 4616239 \\
Number of lung cancer deaths per annum & 7173 & 702 \\
Calculated annual lung resections required (10\% resectability rate) & 717 & 70 \\
ASIR lung carcinoma & 15.2 per 100000 & 15.2 per 100000 \\
Annual incidence based on ASIR & 7144 & 702 \\
Calculated annual lung resections required (10\% resectability rate) & 714 & 70 \\
\hline
\end{tabular}

Table II. Analysis of operation statistics at Universitas Hospital 2004 - 2006 ${ }^{10}$

\begin{tabular}{llllll}
\hline & 2004 & 2005 & 2006 & Total & Annual average \\
\hline Total number of all thoracic operations performed & 132 & 175 & 190 & 497 & 166 \\
Operations for pyogenic empyema & 30 & 25 & 38 & 93 & 31 \\
Lung resections for inflammatory disease (non-TB) & 16 & 16 & 12 & 44 & 17 \\
Lung resections for pulmonary TB & 14 & 17 & 12 & 43 & 14 \\
Lung resections for lung cancer & 6 & 2 & 3 & 11 & 4 \\
\hline
\end{tabular}


non-tuberculous inflammatory pleuro-pulmonary diseases. However, based on the few operations performed annually relative to the size of the population and the severe burden of thoracic disease, it is reasonable to assume that the performance gap extending to all thoracic surgery pathologies is significant. It is unlikely that thoracic surgery in central SA provides for more than $10 \%$ of the probable workload. The performance gap was calculated to be approximately 1:20 for lung cancer and 1:34 for oesophageal cancer. ${ }^{10}$ The overall performance gap is therefore estimated as a factor of $1: 10$, meaning that thoracic surgery provides only $10 \%$ of the required service.

National health reform policy redirecting funding to primary health care facilities has been detrimental to academic units. Poor medical capacity at peripheral facilities and logistical limitations in the referral chain result in many patients being denied timeous specialist care. Furthermore, the understaffing and underfunding of academic units has limited their capacity to assist with meaningful health reforms.

\section{References}

1. Gevers W. Clinical research in South Africa: a core asset under pressure. Lancet 2009; 374: $760-762$.
2. Statistics SA. Primary Tables Free State: Census 1996 and 2001 compared. Pretoria: Statistics South Africa, 2005 (accessed 12 February 2008).

3. Human Sciences Research Council. Fact Sheet Poverty in South Africa 2004. Pretoria: Human Sciences Research Council, 2004. http:/ / www.sarpn.org.za. (accessed 12 November 2007).

4. Statistics SA. Census 2001. Pretoria: Statistics SA, 2004. http://www.statssa.gov.za/census01/ $\mathrm{html} /$ default.asp (accessed 23 November 2007).

5. Bradshaw D, Nannan N, Laubscher R, et al. Mortality Estimates for Free State, 2000. South African National Burden of Disease Study. Cape Town: Medical Research Council, 2004. http:// www.mrc.ac.za/bod/reports.htm (accessed 20 November 2006)

6. Bradshaw D, Nannan N, Laubscher R, et al. South African Burden of Disease Study 2000 Estimates of Provincial Mortality. Cape Town: Medical Research Council, 2004. http://www. mrc.ac.za/bod/reports.htm (accessed 17 November 2006).

7. Linegar AG, Smit F, Goldstraw P, Van Zyl G. Fifty years of thoracic surgery research in South Africa. S Afr Med J 2009; 99: 592-595.

8. Health Systems Trust. Incidence of TB (PTB new Sm+) (per 100 000). Durban: Health Systems Trust, 2006. http://www.hst.org.za/healthstats/163/data (accessed 4 June 2008).

9. Bradshaw D, Groenewald P, R. L, Nannan N, et al. Initial burden of disease estimates for South Africa, 2000. S Afr Med J 2003; 93:682-688.

10. Linegar AG. A model for the development of thoracic surgery in central South Africa. $\mathrm{PhD}$ thesis, University of the Free State, 2008.

11. Mqoqi N, Kellett P, Sitas F, Jula M. Incidence of histologically diagnosed cancer in South Africa, 1989 - 1999. www.nhls.ac.za/Updated\%20cancer98_ALL.pdf (accessed 4 June 2008).

12. Willcox PA, O'Brien JA, Abratt RP. Lung cancer at Groote Schuur Hospital - a local perspective. S Afr Med J 1990; 78(12): 716-720.

13. Linegar AG. The importance of staging in non-small cell lung cancer. SA Resp J 2001; 7 : 144-148.

14. Bradshaw D, Groenewald P, Laubscher R, et al. Initial Burden of Disease Estimates for South Africa, 2000. Cape Town: Medical Research Council, 2004. http://www.mrc.ac.za/bod/ initialbodestimates.pdf (accessed 16 November 2006).

15. Page R, Roxburgh J, Keogh B. Thoracic Surgical Register 2005 - 6. London: Society for Cardiothoracic Surgery in Great Britain and Ireland. http://www.scts.org (accessed 16 November 2007).

16. Toomes H. General thoracic surgery as a monospecialty - a realistic vision? Eur J Cardiothor Surg 2002; 21: 1-4.

Accepted 30 March 2010. 